\title{
SLC2A4 Polymorphisms Can Be a New Molecular Biomarker for Sports Genomics
}

\author{
${ }^{1}$ Kadir Sinan Arslan, ${ }^{2}$ Fatma Akpunar, ${ }^{2}$ Canan Sercan, ${ }^{1}$ Sezgin Kapıcı, ${ }^{1,2}$ Korkut Ulucan* \\ ${ }^{1}$ Üsküdar University, Faculty of Engineering and Natural Sciences, Department of Molecular Biology and Genetics, \\ Istanbul, Turkey. ${ }^{2}$ Marmara University, Faculty of Medical Biology and Genetics, Department of Medical biology \\ and Genetics, Istanbul, Turkey.
}

\section{DEAR EDITOR}

To date, most of the studies were conducted on the genetic SNPs of athletic performance. Angiotensin converting enzyme (ACE) insertion/ deletion and alpha- actinin-3 (ACTN3) R577X are the most widely analyzed polymorphisms in sports genomics $(1,2)$. Besides these, other SNPs are still under investigation, which are considered to have an important effect on athletic performance. But, due to the lack of new hypothesis in sports biology, studies are getting limited by time. Therefore, we need to evaluate new metabolic pathways to understand which factors are important for athletic performance.

Glucose is the most important carbon source and energy supply for almost every cell in our body. Its distribution to tissues through the blood and its transportation from the cell membrane is important for aerobic capacity of the cell. Besides, glucose transportation into muscles is important for normoglycemia. Skeletal muscle stores glucose as glycogen and also oxidizes it to produce energy following its transport step. All animal cells contain a group of membrane proteins involved in transporting glucose into the cell (3). This transportation is maintained by 13 different sugar transporter proteins, GLUT1-
GLUT12 and HMIT (4). These sugar transporters display differences in their kinetics and respective substrate specificities, such that GLUT5 and probably GLUT11 are likely to be fructose transporters.

GLUT4 is highly expressed in adipose tissue and skeletal muscles, but these tissues also express a selective cohort of the other transporters. In skeletal muscles, GLUT1, GLUT5, and GLUT12 may significantly contribute to sugar uptake in addition to GLUT4 (5) whereas in adipose tissue, GLUT8, GLUT12 and HMIT are also involved in sugar uptake $(6,7)$.

In skeletal muscle cells, glucose uptake is carried out by facilitated diffusion, and this process depends on the presence of GLUT4 in the surface membrane. The main regulative sites/processes in this manner are: 1) glucose delivery to muscles, 2) glucose transport from membrane, and 3) glucose utilization. When the cells are under rest, GLUT1 expression is relatively low and muscle GLUT4 proteins reside within intracellular vesicles. Insulin stimulation and exercise acutely trigger GLUT4 protein transportation to the cell surface of muscle and adipose cells, independent of transcription or translation $(8,9)$. Under aerobic

*. Corresponding Author:

Korkut Ulucan

E-mail: korkutulucan@hotmail.com 
conditions, like endurance exercise; GLUT4 translocation from intracellular vesicles to the sarcolemma and T-tubules increase glucose transport. Researchers have reported the importance of GLUT4 for muscle glucose uptake during electrical stimulation in GLUT4 knockout (KO) mice in which muscle contractions has negligible effect on glucose uptake $(10,11)$. In addition to this, muscle glucose uptake is markedly reduced along with exercise tolerance in mice with muscle-specific GLUT4 deletion during exercise (12). And also it is known that increased skeletal muscle GLUT4 expression would also facilitate post-exercise glucose uptake and glycogen storage (13).

Recent studies showed that exercise increases the expression of GLUT4 mRNA and protein. The gene responsible for GLUT4 is SLC2A4 (Gene ID: 6517), that is a member of the solute carrier family 2 (facilitated glucose transporter) member 4. It is located at $7 \mathrm{p} 13$ and has 11 exons. This gene has several SNPs in its promoter, exon, intron and UTR regions, which may have functional alterations in gene metabolism. Up to date, over 50 variations in the gene were reported. Of these, rs2654185, rs5412, rs5418 and rs5435 are the most functional SNPs in the gene.

To date, very limited studies were carried out in the terms of sports genetics, trying to associate athletic performance and SLC2A4 polymorphisms. The $\mathrm{G} \rightarrow \mathrm{A}$ transition (rs5418) in $S L C 2 A 4$ promoter region was shown to alter $S L C 2 A 4$ expression. Although this variation is not located in the coding part and does not possess functional motifs in the protein, it may be very important in gene expression because it is very close to transcription start site (at $30 \mathrm{bp}$ locus of SLC2A4 promoter). Before, GG genotype of rs5418 was reported to have a lower amount of SLC2A4 mRNA when compared to AA and AG genotypes (14). Xia et al. (2014) analyzed 102 top-level long-distance runners (53 men and 49 women) and compared them with 206 healthy controls (118 men and 88 women) in the northern Han Chinese population. Results of the study revealed that AA genotype and A allele of rs5418were associated with top-level endurance performance (15). The same authors also reported the high amount of GLUT4 protein in A allele carriers. But these studies are very limited to understand the effect of these SNPs on athletic performance.

Athlete- sedentary, national athlete- elite athlete studies and comparison of the related SNPs in athletes from different sports types will be very informative studies in the terms of sports genomics. Therefore, future analyses of SLC2A4 polymorphisms and GLUT4 metabolism in athletes in different sports types will help to clarify the importance of the related SNPs in determining athletic performance.

\section{REFERENCES}

1. Ulucan K, Biyik B, Kapici S, Sercan C, Yilmaz O, Catal T. Alpha-actinin-3 R577X Polymorphism Profile of Turkish Professional Hip-Hop and Latin Dancers. Annals of Applied Sport Science. 2016;4(4):1-6.

2. Ulucan K, Göle S. ACE I/D polymorphism determination in Turkish elite wind-surfers. Sport Science Review. 2014;23(1-2):79-84.

3. Elbrink J, Bihler I. Membrane transport: its relation to cellular metabolic rates. Science (New York, NY). 1975;188(4194):1177-84.

4. Joost HG, Thorens B. The extended GLUT-family of sugar/polyol transport facilitators: nomenclature, sequence characteristics, and potential function of its novel members (review). Molecular membrane biology. 2001;18(4):247-56.

5. Stuart CA, Wen G, Gustafson WC, Thompson EA. Comparison of GLUT1, GLUT3, and GLUT4 mRNA and the subcellular distribution of their proteins in normal human muscle. Metabolism. 2000;49(12):1604-9.

6. Wood IS, Hunter L, Trayhurn P. Expression of Class III facilitative glucose transporter genes (GLUT-10 and GLUT-12) in mouse and human adipose tissues. Biochem Biophys Res Commun. 2003;308(1):43-9.

7. Wood IS, Trayhurn P. Glucose transporters (GLUT and SGLT): expanded families of sugar transport proteins. The British journal of nutrition. 2003;89(1):3-9.

8. Herman MA, Kahn BB. Glucose transport and sensing in the maintenance of glucose homeostasis and metabolic harmony. The Journal of clinical investigation. 2006;116(7):1767-75.

9. Rose AJ, Richter EA. Skeletal muscle glucose uptake during exercise: how is it regulated? Physiology (Bethesda, Md). 2005;20:260-70. 
10. Ryder JW, Kawano Y, Galuska D, Fahlman R, Wallberg-Henriksson H, Charron MJ, et al. Postexercise glucose uptake and glycogen synthesis in skeletal muscle from GLUT4-deficient mice. FASEB journal : official publication of the Federation of American Societies for Experimental Biology. 1999;13(15):2246-56.

11.Zisman A, Peroni OD, Abel ED, Michael MD, Mauvais-Jarvis F, Lowell BB, et al. Targeted disruption of the glucose transporter 4 selectively in muscle causes insulin resistance and glucose intolerance. Nature medicine. 2000;6(8):924-8.

12. Fueger PT, Li CY, Ayala JE, Shearer J, Bracy DP, Charron MJ, et al. Glucose kinetics and exercise tolerance in mice lacking the GLUT4 glucose transporter. J Physiol. 2007;582(Pt 2):801-12.

13. Greiwe JS, Hickner RC, Hansen PA, Racette SB, Chen MM, Holloszy JO. Effects of endurance exercise training on muscle glycogen accumulation in humans. Journal of applied physiology (Bethesda, Md : 1985). 1999;87(1):222-6.

14. Malodobra-Mazur M, Bednarska-Chabowska D, Olewinski R, Chmielecki Z, Adamiec R, Dobosz T. Single nucleotide polymorphisms in 5'-UTR of the SLC2A4 gene regulate solute carrier family 2 member 4 gene expression in visceral adipose tissue. Gene. 2016;576(1 Pt 3):499-504.

15. Xia X, Hu Y, Xu L, Chen T. A functional promoter polymorphism of SLC2A4 is associated with aerobic endurance in a Chinese population. European journal of sport science. 2014;14(1):53-9. 